Int. J. Electrochem. Sci., 13 (2018) 10564 - 10586

\title{
Copper(II) Trace Determination in Aqueous/Ethanolic Medium Using an Ionic Imprinted Hybrid
}

\author{
Paulo Cesar Mendes Villis ${ }^{1, *}$, Wolia Costa Gomes ${ }^{1}$, Fabricio Brito Silva ${ }^{l}$, Diego Rosa dos Santos ${ }^{1}$, \\ Gustavo Silveira ${ }^{2}$, Andréia de Morais ${ }^{2}$, Rodrigo Vieira Blasques ${ }^{3}$, Gilvanda Silva Nunes ${ }^{3}$, \\ Fábio Luiz Pissetti ${ }^{2}$, Yoshitaka Gushikem ${ }^{4}$ and Alzira Maria Serpa Lucho ${ }^{2}$ \\ ${ }^{1}$ Laboratory of Materials and Electrochemistry- LME, University of CEUMA - UNICEUMA, 65.065- \\ 470, São Luís, MA, Brazil \\ ${ }^{2}$ Institute of Chemistry, Federal University of Alfenas - UNIFAL-MG, 37130-000, Alfenas, MG, \\ Brazil \\ ${ }^{3}$ Nucleus of Pesticide Residue Analysis- NARP, Federal University of Maranhão - UFMA, 65.080- \\ 040, São Luís, MA, Brazil \\ ${ }^{4}$ Institute of Chemistry, State University of Campinas - UNICAMP, Inorganic Chemistry, Campinas, \\ SP, Brazil \\ *E-mail: paulo.villis@ceuma.br
}

doi: $10.20964 / 2018.11 .68$

Received: 13 April 2018 / Accepted: 18 August 2018 / Published: 1 October 2018

In this work, an ionic imprinted hybrid material organically modified with 3-(2-imidazolin-1yl)propyltriethoxysilane with copper(II) as template was prepared and structurally characterized, using elemental analysis, X-ray powder diffraction (XRD), thermogravimetric analysis, infrared spectroscopy and solid state ${ }^{13} \mathrm{C}$ and ${ }^{29} \mathrm{Si}$ nuclear magnetic resonance (NMR). Experiments with cyclic voltammetry and differential pulse anodic stripping voltammetry (DPASV) showed that the electrode prepared was stable over 100 cycles, with high reproducibility. Copper(II) ions could be quantified in water/Brazilian sugar cane spirit (cachaça). Calibration curve for detection was obtained from $5.98-$ $201.42 \mu \mathrm{g} \mathrm{L}^{-1}$ of copper(II) concentration, with a correlation coefficient of $\mathrm{R}^{2}=0.995 ; \mathrm{n}=12$. The detection limit obtained was (LOD) as $0.74 \mu \mathrm{g} \mathrm{L}^{-1}$ and the limit of quantification (LOQ) was of 2.48 $\mu \mathrm{g} \mathrm{L}^{-1}$ in water/cachaça. The interference studies in presence of $\mathrm{Na}(\mathrm{I}), \mathrm{Fe}(\mathrm{II}), \mathrm{Pb}(\mathrm{II}), \mathrm{Ni}(\mathrm{II})$, and $\mathrm{Zn}(\mathrm{II})$ do not significantly affected the peak currents, with high recovery of copper(II) in the range $91.20 \%$ to $109.11 \%$ in ethanolic medium and $89.54 \%$ to $116.78 \%$ in aqueous medium. The DPASV technique was used to determine copper(II) in commercial samples in aqueous/ethanolic medium such as tap water, cachaça and ethanol fuel and the results were compared with the values found by flame atomic absorption spectrometry (FAAS).

Keywords: hybrid material; imidazole; copper(II); tap water; cachaça; ethanol fuel 


\section{FULL TEXT}

(C) 2018 The Authors. Published by ESG (www.electrochemsci.org). This article is an open access article distributed under the terms and conditions of the Creative Commons Attribution license (http://creativecommons.org/licenses/by/4.0/). 